\title{
Bimodal Distribution of Thyroid Dysfunction Triggered by Covid-19 Infection. An Experience From a Single Endocrine Centre. A Short Report \& Literature Review
}

\author{
Tarik A Elhadd ( $\nabla$ tarikelhadd58@gmail.com ) \\ Hamad Medical Corporation \\ Wajiha Gul \\ Hamad Medical Corporation \\ Zeinab Dabbous \\ Hamad Medical Corporation \\ Stephen Beer \\ Hamad Medical Corporation \\ Mohammed Bashir \\ Hamad Medical Corporation
}

\section{Short Report}

Keywords: Thyroid, Hyperthyroidism, Thyroiditis, hypothyroidism, subacute thyroiditis, Grave's disease, Severe Acute Respiratory Distress Syndrome Coronavirus 2 (SARS-CoV2), Covid-19

Posted Date: February 22nd, 2022

DOl: https://doi.org/10.21203/rs.3.rs-1374849/v1

License: (c) (1) This work is licensed under a Creative Commons Attribution 4.0 International License. Read Full License 


\section{Abstract}

Purpose: Covid-19 infection has been spreading across the globe since the end of 2019 and it continues to cause chronic multi-system sequalae, of which thyroid dysfunction appears to be a major one. We aim to present cases

Methods: Case series report.

Results: Over the period from October 2020 to July 2021, a series of 10 cases of thyroid dysfunction due to Covid-19 infection were seen and managed in a single outpatient endocrine centre in Doha, Qatar. These are 6 cases of Graves hyperthyroidism, two cases of chronic primary hypothyroidism including one with GD treated by RAl therapy, two cases of subacute thyroiditis and one case with 'Thyroxin Thyrotoxicosis', and finally one case of central hypothyroidism.

Conclusion: This report is the largest to be reported from a single centre so far, and it points to a bimodal distribution of thyroid dysfunction in patients with covid-19 infection. A review of the literature and discussion of possible pathophysiological mechanisms is presented. We stress the importance of screening for thyroid dysfunction in post-Covid cases, as the prevalence may be underestimated.

\section{Introduction}

For over two years the world has been battling the health impact stemming from the Severe Acute Respiratory Syndrome Coronavirus 2, (SARS-CoV-2,), also known as Covid-19, which was first witnessed in Wuhan in 2019/2020 winter. The virus classically presents with respiratory symptoms but could well be asymptomatic or may even present with atypical presentation with non-pulmonary complications that include neurological disorders, cardiac abnormalities, renal failure, liver disease, rhabdomyolysis, coagulopathy and thrombosis, and endocrine dysfunction. SARS-CoV-2 uses ACE- 2 receptor and transmembrane protease serine 2 (TMPRSS2), and Cathpesin to gain access and infect human cells (1). Infection or entry will trigger a cascade of virus replication and release of virus with resultant cell damage. This process is called pyroptosis, an abrupt form of programmed cell death (2), with subsequent cascade of events that include a release of an array of cytokines (e. g. interleukins, TNF \& INF), in addition to intracellular molecules, like ATP, nucleic acids and damage associated nuclear patterns (PAMPs). The proinflammatory cytokines (IL- $\beta, T N F a-$, INF- $\varangle$, etc), may lead to immune response hyperactivity and uncontrolled systemic inflammatory response (2). Enhanced Th1/Th17 immune responses and cytokine pathways involved in SARS resemble in some way the immune activation that occurs in immune mediated thyroid disease (3). ACE-2 \& Transmembrane protease serine 2 (TMPRSS2) expression is very high in the thyroid more than in the lungs (4).

Uptake by host cells of SARS-Covid-2 is thought to be mediated by other cellular proteases and molecules. One main group of cellular membrane protein involved was found to be the integrins, and ACE2 binds to integrins to modulate downstream signal transduction. T4 regulates expression of genes for the monomeric protein that makes up integrins (5). Thyroid hormones regulate genes for the monomeric protein that makes up integrins and they are also deemed to promote internalization of the integrins $(6,7)$. Worth noting is that 
olfactory receptors (ORs) are co-expressed with ACE2 and TMPRSS2. ORs are widely expressed in the thyroid (8). Impairment of the cellular function at the neuro-epithelium of the Olfactory bulb constitutes the molecular mechanism that underlies the anosmia observed in Covid victims (9). The damage to ORs is postulated to be contributing to the impairment of other organs expressing OR not excluding the thyroid (8).

Viruses has been well recognized to trigger thyroid autoimmunity (10). Thyroid disease in the context of Covid-19 infection has been shown in a recent systematic review and metanalysis to be associated with poor outcome (11). However, the relationship of the two has been described as bidirectional (12). In this short report, we present a fiesta of a diverse 8 cases of thyroid dysfunction associated with Covid-19 infection that were diagnosed and managed in a single endocrine centre in Qatar. We have also reviewed the literature related to the subject.

\section{Case Presentations}

1- Case 1: A young 49-year-old Sudanese gentleman, with history of bronchial asthma, hypertension, prediabetes and gout, was tested positive for Covid on 24 November 2020. He had PCR as mandatory screening, which was done upon arrival to Qatar as a part of preventive measures to curb the spread of the coronavirus. Upon questioning, he gave history of headache and fever over the preceding few days along with multiple episodes of vomiting and diarrhea (around 4 times a day). However, these subsided two days later. On questioning, patient denied any cough, shortness of breath or sore throat. He was diagnosed with Covid pneumonia and was started on the anti-retroviral favipiravir and transferred to a quarantine facility. No thyroid function tests (TFTs) was done during this time. He had TFT in May 2019, and that was normal. He made an uneventful recovery from Covid. Two months later, the patient had general checkup as he complained of slight increase in body weight. Here, TFT showed TSH of 33.49 mu/l (NRR 0.4-4.5mu/I), and free T4 of 8pmol/I (NRR 8-18pmol/I). Repeat TFTs done 6 weeks later revealed TSH of 34.22mu/I and T4 dropped further to $7.4 \mathrm{pmol} / \mathrm{l}$. At this point he was referred to our endocrine clinic.

When reviewed at our clinic, he denied any history of tiredness, fatigue, sleepiness or other symptoms of hypothyroidism other than weight gain. He has no family history of goitre or thyroid dysfunction. He was not on any medication which may cause perturbation of thyroid function. On examination; BP: 128/84, Pulse: 74, BMI: $29.06 \mathrm{Kg} / \mathrm{m}^{2}$. He was clinically euthyroid with no neck swelling, and unremarkable physical exam. Tests done showed TSH 49 mU/I, FT 11 pmol/I. Anti-TPO Ab was 423 IU/ml (Normal <30), TSH-RAb was negative. Neck US showed heterogenous thyroid with minimally increased vascularity and a small hyperechoic nodule measuring $5 \times 4 \mathrm{~mm}$. Thyroid uptake scan showed normal morphology and function except for a cold nodule in the postero-inferior part of the right lobe.

After discussion with the patient, it was decided to wait and see policy. Repeated TFT after 6 weeks showed TSH has risen to $61 \mathrm{mIU} / \mathrm{I}$ and FT $4 \mathrm{pmol} / \mathrm{I}$. He was started on levothyroxine $100 \mathrm{mcg}$ daily and TFT normalized after 6 weeks.

2- Case 2: A 50-year-old Filipino male, with past medical history of asthma and hypertension, presented with respiratory symptoms and he tested positive for Covid-19 infection. Chest x-ray showed bilateral lung infiltrates. He was treated as Covid-19 pneumonia and started on treatment as per hospital protocol 
(azithromycin: 500mg daily, ceftriaxone 2gm IV once daily, hydroxychloroquine 400mg daily, lopinavir/ritonavir 200/50mg bid, ribavirin and oseltamivir $150 \mathrm{mg}$ bid). His hospital course was complicated by ARDS requiring ICU admission. He received Tociluzimab and methylprednisolone but did not require endotracheal intubation or mechanical ventilation. TFTs were done because of persistent tachycardia, and that showed TSH; $0.08 \mathrm{mu} / \mathrm{l}$, FT3 $3.4 \mathrm{pmol} / \mathrm{l}$ (NRR 3-6), FT4 23. When TFT was repeated few weeks later it showed resolution of thyroid dysfunction with TSH 0.47 , and FT4 $18.8 \mathrm{pmol} / \mathrm{l}$, suggesting 'Thyroxine Thyrotoxicosis' due to Covid-19 related thyroiditis. Subsequent follow up over 6 months revealed no further abnormality.

3- Case 3: 32 years old female Sudanese patient had hypothyroidism during adolescence for which she was treated with levothyroxine till the age of 16 years. She has been euthyroid since then. She also has previous history of thyroid nodule in 2016 for which she had no follow up since then. In September 2020, she was diagnosed with Covid-19 infection following a mild respiratory illness. She made uneventful recovery, but 3 months later in December 2020, she presented with symptoms of tiredness, fatigue, bilateral hand tremors, palpitations, increased sweating, shortness of breath and irregular periods. Physical examination was consistent with hyperthyroid state with a small diffuse goitre. TFTs showed TSH<0.01, FT4: $72.3 \mathrm{mIU} / \mathrm{I}$, TSHRAb $28 \mathrm{U} / \mathrm{l}$ (Normal<0.75). Thyroid nuclear uptake scan with technetium revealed enlarged thyroid with overall picture suggestive of diffuse Grave's disease. She was started on carbimazole $30 \mathrm{mg}$ daily along with propranolol 40mg bid and she improved. Repeated TFT after 2 months showed TSH<0.01, FT3: 7.6 and FT4: 24.0. Subsequent repeat TFTs showed normal level. She is being followed up in the Endocrinology clinic for her Grave's disease, and latest TFTs done in January 2022 showed persistent remission with carbimazole.

4- Case 4: A 40 year old Filipina lady with history of asthma on salbutamol inhaler, was admitted to hospital with Covid-19 pneumonia of mild to moderate severity. She was started on COVID treatment as per hospital protocol (Hydroxychloroquine, oseltamivir and azithromycin). She was noticed to have persistent tachycardia, so TFT done, and that showed hyperthyroidism with TSH <0.01, FT3 $30.8 \mathrm{pmol} / \mathrm{l}$, and FT4 83.3 $\mathrm{pmol} / \mathrm{l}$. Anti-TPO Abs; $494 \mathrm{IU} / \mathrm{ml}$. TRAb was elevated at $8.7 \mathrm{iu} / \mathrm{l}$. She was started on carbimazole, however, she stopped it after discharge thinking that it is a Covid medication. 8 months later she presented to the ER with severe abdominal pain and vomiting. On exam, BP: $211 / 110$. Heart rate: $136 / \mathrm{min}$, with small goitre, otherwise no other signs of hyperthyroidism. CT abdomen showed intestinal obstruction. Labs: $\mathrm{TSH}<0.01$, FT3: $32.9 \mathrm{pmol} / \mathrm{I}, \mathrm{FT} 4>100 \mathrm{pmol} / \mathrm{l}$, and TSH-RAb elevated at $7.7 \mathrm{u} / \mathrm{l}$. Her Bursch Wartofsky's score was 35, so she was treated as impending thyroid storm. Neck US revealed enlarged thyroid lobes with increased vascularity. The intestinal obstruction was managed conservatively. She improved and was discharged home on carbimazole $20 \mathrm{mg}$ bid and metoprolol $75 \mathrm{mg}$ bid. On follow up, she remained euthyroid.

5- Case 5: A 40 year old male referred to Endocrine clinic for hyperthyroidism. He stated that he had symptoms of loss of taste and smell, muscle aches and pains 3 months ago, however, he didn't get tested for COVID. Later after 2 to 3 months, he developed symptoms of weight loss and anxiety and was referred to endocrinology clinic. His TSH was $<0.01$, FT4; $100 \mathrm{pmol} / \mathrm{l}$. He was started on carbimazole $40 \mathrm{mg} / \mathrm{day}$, and on follow up his TFTs normalized. The presumptive diagnosis is Grave's disease precipitated by COVID.

6- Case 6: A 14-year-old Qatari girl was referred to the endocrine clinic in November 2020, for possible hyperthyroidism. All family including the patient suffered mild Covid-19 infection, and all made uneventful 
recovery. On assessment, she was noted to be tremulous, and mentioned that she had lost some weight of around $6-8 \mathrm{Kg}$ and then she began to have palpitations. TFTs showed TSH $<0.02 \mathrm{mU} / \mathrm{l}, \mathrm{T} 4,35 \mathrm{pmol} / \mathrm{I}$. She was given propranolol, $10 \mathrm{mg}$ tid. Repeat TFTs, 5 weeks later in January 2021, showed TSH $5.6 \mathrm{mu} / \mathrm{l}$, and FT4, 25 pmol/l. Repeat TFTs on 15 of March 2021 showed TSH 7.5 mu/l \& FT4 17 pmol/l. Further TFTs confirmed euthyroidism with complete resolution of the abnormalities.

7- Case 7: A 32-year-old Filipina female with no history of any medical illness in the past, contracted COVID19 infection in October 2020. She had mild illness and made an uneventful recovery with symptomatic treatment only. However, four weeks later she was seen in Endocrinology clinic, where she was referred with symptoms of weight loss, palpitations, increased sweating and shakiness. Clinically she was in a hyperthyroid state. TFT: TSH; <0.01 mU/l, FT4: 46 pmol/l, TRAb: 8.7, and Anti-TPO ab: 73iu/l. US thyroid showed bilateral enlarged thyroid lobes with increased vascularity. She was diagnosed with Grave's disease and started on carbimazole $30 \mathrm{mg}$ daily and propranolol, $40 \mathrm{mg}$ bid. On follow up, she remained euthyroid clinically and biochemically.

8- Case 8: A 33-year-old Filipino gentleman was diagnosed with Graves' hyperthyroidism in September 2020, following symptoms, TSH $<0.001$, T4 >100pmol/l, T3 $39 \mathrm{pmol} / \mathrm{l}$, TRAb 33, and anti-TPO Abs of 119 (NRR, 40IU). He was started on carbimazole, and he achieved remission in few months, and in January 2021 he received radioactive iodine therapy as a definitive treatment. He remained in remission following that and on the 19th of April 2021 got infected with Covid-19 infection which ran a mild course requiring only simple analgesics. On the 3rd of May 2021 he was seen for profound tiredness and TFTs showed a TSH of 90mu/l and $\mathrm{T} 4<4 \mathrm{pmol} / \mathrm{I}$. He was started on levothyroxine $100 \mathrm{mcg}$ and on follow up required replacement therapy.

9- Case 9: A 33-year-old Indian lady was diagnosed with uncomplicated Covid-19 infection in June 2021, and in August she was reviewed by her primary care physician for intense aches and pains, and joint discomfort. Investigation revealed only picture consistent with central hypothyroidism, with low free T4 of $4.1 \mathrm{pmol} / \mathrm{I}$ and TSH inappropriately low at $6.5 \mathrm{mu} / \mathrm{I}$. Serial TFTs up to early December 2021 confirmed persistent central hypothyroidism, which necessitated thyroxine replacement therapy. Tests for pituitary function all showed normal results. Symptoms resolved following thyroxine treatment.

10- Case 10: A 51-year-old Filipina lady was seen in August 2021. New referral from PHCC. Had thyrotoxicosis 15 years ago. Had 2 years of medication, then stopped, fine since. Recent Covid-19 infection on 17th of June 2021, good recovery, but has lost weight and felt eye bulging again. TFTS confirm hyperthyroidism, with TSH 0.005, FT3 16.3 pmol/l, FT4 52.5pmol/l, TRAb 9.3 iu/l. No other significant PMH. She had TFTs in November 2020 which was normal with TSH 0.92 mu/l, FT4 19pmol/l. Was started on carbimazole and that resulted in good response with remission in the following 2 months. Latest TFTs showed persistent remission on maintenance carbimazole.

Table 1 summarizes the above 10 cases of thyroid dysfunction related to COVID-19 infection. 
Table 1

\begin{tabular}{|c|c|c|c|c|c|c|}
\hline $\begin{array}{l}\text { Clinical } \\
\text { Characteristics }\end{array}$ & Age & Gender & $\begin{array}{l}\text { History of } \\
\text { Thyroid } \\
\text { Disease }\end{array}$ & Diagnosis & $\begin{array}{l}\text { Presentation } \\
\text { Since COVID } \\
\text { Infection }\end{array}$ & $\begin{array}{l}\text { Treatment } \\
\text { Received }\end{array}$ \\
\hline Case 1 & 49 & Male & No & Hypothyroidism & 6 weeks & Levothyroxine \\
\hline Case 2 & 50 & Female & No & $\begin{array}{l}\text { Sick Euthyroid } \\
\text { Illness }\end{array}$ & $\begin{array}{l}\text { During } \\
\text { admission } \\
\text { for COVID } \\
\text { Pneumonia }\end{array}$ & None \\
\hline Case 3 & 32 & Female & Hypothyroidism & Grave's disease & 3 months & Carbimazole \\
\hline Case 4 & 40 & Female & No & $\begin{array}{l}\text { Grave's } \\
\text { disease... } \\
\text { stopped } \\
\text { antithyroid } \\
\text { drugs } \\
\text { prematurely } \\
\text { and later } \\
\text { presented with } \\
\text { Thyroid Storm }\end{array}$ & $\begin{array}{l}2 \text { weeks } \\
\text { initially, later } \\
\text { with thyroid } \\
\text { storm after } \\
8 \text { months }\end{array}$ & $\begin{array}{l}\text { Carbimazole } \\
\text { \& Propranolol }\end{array}$ \\
\hline Case 5 & 40 & Male & No & Grave's disease & 2-3 months & $\begin{array}{l}\text { Carbimazole } \\
\text { \& Propranolol }\end{array}$ \\
\hline Case 6 & 14 & Female & No & Thyroiditis & 6 weeks & Propranolol \\
\hline Case 7 & 32 & Female & No & Grave's disease & 4 weeks & $\begin{array}{l}\text { Carbimazole } \\
\text { \& Propranolol }\end{array}$ \\
\hline Case 8 & 33 & Male & Yes & $\begin{array}{l}\text { Hypothyroid } \\
\text { post } \\
\text { Radioactive } \\
\text { lodine ablation } \\
\text { for Graves } \\
\text { disease }\end{array}$ & 2 weeks & Levothyroxine \\
\hline Case 9 & 33 & Female & No & $\begin{array}{l}\text { Central } \\
\text { Hypothyroidism }\end{array}$ & 2 months & Levothyroxine \\
\hline Case 10 & 51 & Female & Yes & Grave's disease & 2 months & Carbimazole \\
\hline
\end{tabular}

\section{Discussion}

Covid-19 infection continues to ravage the world population, and its effect proved to have diverse with multisystem consequences. Covid-induced thyroid dysfunction is emerging as well established and common aftermath of the disease. As is shown by our cases, the clinician in endocrine practice could well be faced by protean and diverse presentations. Four of our eight cases presented with immune mediated hyperthyroidism, and the remaining four all had virus-induced destructive thyroiditis, which proved to be transient in two cases, and have a permanent effect in the other two. Triggering of various autoimmune disease in general by Covid-19 has been recognized, that includes anti-phospholipid syndrome, autoimmune 
thrombocytopenia, haemolytic anaemia, Gillian Barre, syndrome, to name but a few (13). This may persist long after the resolution of Covid-19.

The literature shows that non-thyroidal illness (NTI) is the most common abnormality observed in Covid-19 patients. Up to $30 \%$ of Covid-19 patients, may suffer the syndrome of low TSH with low or normal T4, and low T3 (14). NTI may occur at all spectra of the illness. It commonly occurs with the 'Cytokine Storm' also known as Cytokine Release Syndrome $(15,16)$, The degree of reduction of TSH and FT3 is proportional to the severity of Covid infection (17). Those with low T3, generally have low fT3/fT4 ratio $(<0.3)$ suggesting a reduced 5-mono-deiodinase activity (both D1 \& D2), that converts T4 to T3. There is also increased activity of D3 that catalyses deactivation of both T4 and T3. In our series, which is exclusively an outpatient activity, we have not seen this abnormality. All our cases had recovered from their acute Covid-19 infection, and whether they had an initial picture of NTI followed by a more florid presentation to specific clinical phenotype could not be established, as none had been tested for thyroid dysfunction during their Covid-19 infection.

Viral infection is frequently cited as an environmental trigger for autoimmune thyroid disease (18). The evidence for Covid-19 virus to amplify or promote autoimmune thyroid disorders is strong. Several cases of Graves' Disease have been reported since the zenith of pandemic in 2020. Most cases occurred a month or two following Covid-19 infection $(19,20,21,22)$. These reports are in accord with our own observations. A previous history of Graves' disease in remission was observed in most of these cases. One of our four cases had prior history of GD, and one had history of possible immune mediated hypothyroidism for several years, before it resolved completely, suggesting a switch from previous blocking antibody status to stimulating antibody triggered by Covid-19. Harris et al reported a case in which a young healthcare worker developed severe thyrotoxicosis after being recovered from mild COVID-19 infection (23). Jimenez-Blanco et al, reported 2 cases of Grave's disease in remission since 2014 and 2015, who presented with severe recurrence of disease more than one-month post COVID infection, improved with antithyroid medications. All were in the age range of 21-61 years. All had classical biochemical evidence and florid clinical symptoms of Graves' hyperthyroidism, and most had positive TRAb. Radioisotope scan was done in 6 cases. All cases were treated with ATDs and made good response. One case (22) had concomitant Graves' Orbitopathy at the time of the onset, a feature not observed in other reports.

On the other hand, Lania et al in a retrospective analysis, found a prevalence of hyperthyroidism in $20 \%$ of a group of 287 patients hospitalized for Covid-19 patients, with $48 \%$ of those affected had florid hyperthyroidism (24). The incidence of hyperthyroidism correlated with the severity of Covid infection as it was more prevalence in those with pneumonia (25). So, this may point to a bimodal nature of hyperthyroidism triggered by Covid-19, occurring either at the time of acute illness, and this mostly as transient or subclinical (24), or occurring one to two months on average with a more protracted form of hyperthyroidism akin to Graves' hyperthyroidism. Two of our four cases had similar clinical course.

In our cohort, we realized that Covid-19 induced thyroid dysfunction is more common in the ethnic group who normally have the high preponderance of autoimmune hyperthyroidism in our multi-ethnic, multicultural background population. This may suggest a genetic/ethnic component to the predisposition to the development of Covid-19 induced hyperthyroidism. However, this awaits further confirmation in other population. 
Destructive thyroiditis, which could be subclinical or clinical, may take the form of either subacute thyroiditis (SAT, De Quervain thyroiditis), or painless thyroiditis. This is well recognized to be associated with many viruses, like mumps, adenovirus, Epstein Barr virus, cytomegalovirus, influenza virus, and Hepatitis E $(26,27)$. Several case reports of SAT due to Covid-19 have been reported in the literature since the onset of the pandemic $(28,29,30)$. A subacute disease occurring in $10-20 \%$ of Covid-19 patients, may occur either simultaneously with Covid-19, especially those with severe disease admitted in ICU (24), or during the few weeks to months following its resolution, as occurs in our cases as well as those of (31). Neither autoimmune nor non-immune thyroid disease are risk factors for SAT. Neck pain is the hallmark of the disease in SAT. The classical course includes an initial phase of hyperthyroidism followed by hypothyroidism, then euthyroidism, which unfolds over a period of 6 month. The outcome would be either complete resolution $(30,32)$ or development of permanent hypothyroidism (31). Our series had two cases of SAT, one of them, the young girl, recovered completely, and the second one went on to develop permanent hypothyroidism requiring replacement thyroxine therapy. A variant of subacute thyroiditis, which occurs in $15 \%$ as a form of 'SAT' without neck pain, which is thought to be due to lymphopenia (33), which was first recognized in critically ill patients admitted to ICU (34). The biochemical hallmarks comprise low TSH, low FT3 and normal or high FT4, hence the synonym 'Thyroxine thyrotoxicosis'. This is represented in our third case with thyroiditis. This variety is more frequent in males, which could be explained by the gender difference in the immune signatures associated with ACE2 at the thyroid level. Our last case falls in this category, which is not commonly seen. Recently, Trimboli et al, published a systematic review of SAT due to Covid-19 (35). They confirmed that, $83 \%$ of SAT cases occurs after Covid-19 infection, with a female preponderance, onset within three days to two months of the primary infection, and age range of 18 to 69 years, and complete remission in most, with residual hypothyroidism ensuing in only $14.8 \%$ of cases. One of our two cases, was the youngest to be reported with SAT due to Covid infection

Primary hypothyroidism is a rare complication, only in around $5 \%$ of cases, being subclinical in $90 \%$, and clinical in $10 \%$ (24), and it is due to chronic autoimmune thyroiditis. A second study from Iran showed a similar prevalence (36). A prospective study of hospitalized patients from Hong Kong also showed that elevated TSH is a rarity among those with Covid-19 infection and abnormal TFTs (16). It may occur during or after Covid (37). This is exemplified by our first case in the series. He developed hypothyroidism about two months after contracting Covid-19 infection. After observing for over three months, (as he was asymptomatic), thyroid function abnormalities did not resolve and was started on levothyroxine, following which TFT normalized. Of interest is our last case (Case 8), who developed severe and profound hypothyroidism few weeks after Covid-19 infection. Despite the possibility of radioiodine -induced hypothyroidism in his case but taking into the account the rapidity of the hypothyroidism following the Covid-19 infection and the fact that he remained euthyroid between January and April, points either to a direct effect or an amplifying effect of the corona virus.

Worth noting that central hypothyroidism is rare, with reversal of hypothyroidism in most cases. This may represent a transient effect on HPT axis. (38) reported that four (6.7\%) SARS patients three months following recovery were biochemically hypothyroid, comprising three with central hypothyroidism and one with primary hypothyroidism due to new-onset chronic lymphocytic thyroiditis (39). While central hypothyroidism spontaneously remitted in the three patients with central hypothyroidism after three to nine months, most 
cases with primary hypothyroidism generally required permanent T4 therapy (39). However, our experience of only one case suggests that the outcome may not be predictable, and therapy will be required for symptoms and persistent biochemical hypothyroidism. About 5.2\% (15/287) of patients in the study by Lania et al, developed primary hypothyroidism, which was subclinical in about $90 \%$ of cases and overt in the remaining $10 \%$ (24). In the study by Leoew et al, other two cases of primary hypothyroidism due to chronic autoimmune thyroiditis (CAT) were recorded among patients with Covid-19 admitted to high intensity of care units (HICUs) (38). It seems that in both cases primary hypothyroidism developed during Covid-19 and persisted after discharge (38).

The thyroid may be indirectly damaged as hyperactivity of the Th1/Th17 (39) and the surge of 'Cytokine Storm' may trigger and perpetuate the thyroid gland inflammation (2). Lania et al, showed an inverse relationship between TSH and level of IL-6 in their cohort of 287 patients studied (24). This may suggest a role for the cytokine in perpetuating the thyroid dysfunction. On the other hand, an extensive injury to the 'follicular and parafollicular' cells by the virus were reported by some studies (40). This may shed some light for the captivating explanation of increased risk of osteonecrosis in Covid patients $(41,42)$. Impairment of the hypothalamic-pituitary thyroid axis may play a role as SARS genomic sequence were detected in the hypothalamus, and immune-histochemistry of adenohypophysis revealed that both the number and immune reactivity of thyrotrope cells were reduced (43).

Postulated Mechanisms of the trigger of Graves' hyperthyroidism was reviewed by Murugan \& Alzahrani (39). The appealing role of the Corona virus in triggering thyroid autoimmunity is supported by several cases of thyroid dysfunction triggered by the vaccines developed from these viruses $(44,45,46)$, or worsening of pre-existing Graves' following vaccination (47). The phenotypic expression of thyroid autoimmunity has been thought that it is a balance between Th1 and Th2. A predominant Th1 mediated immune response is likely to trigger apoptopic pathway in the thyroid follicular cells resulting in destruction of thyroid cells. Th2 immune mediated activity is likely to activate antigen specific B lymphocytes to make TSH-RAb that results in proliferation of thyroid cells and their hyperactivity of the gland. Stress has been shown to shift the balance towards Th2 that favours development of GD. Further, regulatory CD4+ T cells (Tregs) inhibit effector T cells, and these could differentiate into Th1, Th2 or Th17 and this is dependent on the cytokine milieu. Activity of these cells lines has been shown in animal models to augment cytokine production and activation of autoimmune diseases. SARS-Cov-2 has evidence to be associated with hyper-inflammation that induces Th17 (39). These suggest that viral-induced Graves' disease is likely to be mediated by Th17.

In conclusion, the evidence for Covid-19 virus in causing thyroid dysfunction is accumulating, with a bimodal distribution, occurring with the acute infection as well as during the recovery period. Our report gives further support to this notion. Despite that there are no well-defined risk factors, with the possible exceptions that those with previous history of autoimmune thyroid disease may be more vulnerable, and those who are ethnically more vulnerable to thyroid dysfunction may be most at risk. However, this is only from observation of the few reported cases that accumulated so far. Further, the overall thyroid dysfunction is clinically meaningful to the extent that warrants more vigilance. Screening in the follow up period is therefore highly warranted in patients who recovered from Covid-19 infection, as thyroid dysfunction, as shown in our series may occur weeks to months after the acute phase of the disease. Further, as shown by clustering of cases 
among those who had previous history of thyroid autoimmunity, and also those who are generally ethnically or genetically predisposed, therefore it would be desirable to consider them as among the highest vulnerable group. This may help to elucidate the exact epidemiology of the thyroid disease in Covid-19 era. The other possible contributory mechanisms could be the role of anti-retroviral therapy, role of other factors as secondary modulators, family history, pre-existing thyroid disease/autoimmunity, sex, other environmental factors triggered by the pandemic needs to be also explored.

\section{Abbreviations}

Graves' disease: GD

Severe Acute Respiratory Syndrome Coronavirus 2; SARS CoV-2;

Thyroid Stimulating Hormone: TSH.

Free T4: FT4.

Free T3: FT3.

Coronavirus Disease 2019: COVID-19.

Emergency Department; ED.

Hamad Medical Corporation: HMC.

Medical Research Council: MRC.

\section{Declarations}

\section{Ethical Approval and Consent to participate:}

The case series report was approved by the Medical Research center, Hamad Medical Corporation, Doha, Qatar. A waiver of informed consent was obtained as the report does not contain any identifiers of patients involved.

\section{Consent for publication:}

Consent for publication was approved by the Medical Research center, Hamad Medical Corporation, Doha , Qatar.

\section{Availability of supporting data:}

Data is protected in cerner under Hamad Medical Corporation Regulations.

\section{Acknowledgements:}

None 


\section{Authors Contribution:}

Tarik Elhadd advocated the original idea, initial draft of paper was made by Wajiha Gull, and was later redrafted and expanded by Tarik Elhadd. Zeinab Dabbous, Stephen Beer and Mohammed Bashir contributed to the discussion, idea formulation, writing and reviewing of the manuscript. Patients were looked after by all authors.

\section{Competing Interest:}

No conflict by interest is declared by Tarik Elhadd, Wajiha Gull, Zeinab Dabbous, Stephen Beer \& Mohammed Bashir.

\section{Research Funding:}

None

\section{References}

1. Li MY, Li L, Zhang Y, Wang XS. Expression of the SARS-CoV-2 cell receptor gene AEC in a wide variety of human tissues. Infect Dis Poverty. 2020; 9(1):45 I.

2. Croce $L$, Gangemi D, Ancona, G, et al. The cytokine storm and thyroid hormone changes in Covid 19. J Endocrinol Invest. 44(1): 1-14, 2021.

3. Li Q, Wang B, Mu K et al. The pathogenesis of thyroid autoimmune diseases: New T lymphocytescytokines circuit beyond the Th1-Th2 paradigm. J Cell Physiol 234(3), 2204-2216 (2019

4. The Human Protein Atlas- Tissue Expression of ACE. Available, https:IIwww.proteinatlasorg/ENSG00000130234-ACE2/tissue).

5. Sigrist CJ, Bridge, Mercier P. A potential role for integrins in host cell entry by SARS-CoV-2. Antiviral Res. 2020; 177:104759.

6. Davis PJ, Goglia F, Leonard JL. Nongenomic actions of thyroid hormones. Nat Rev Endocrinol. 2016; 12(2), 111-21,

7. Davies PJ, Lin HY, Herebergs A, Keating KA, Mousa SA. Coronaviruses and integrins av $\beta 3$; does thyroid hormones modify the relationship? Endocrine Res. 2020; 45(3):210-5

8. Kerslake R, Hall M, Randeva HS, et al. Coexpression of peripheral receptors with SARSCov2 infection mediators: potential implications beyond loss of smell as a COVID 19 symptom. Int J Mol Med 2020;46(3)949-56).

9. Pelligrino R, Cooper KW, Di PizioA. et al. Corona viruses and the chemical senses: Past, present and future. Chem Senses. 2020;bjaa031).

10. Tomer Y, Davies TF. Infection, thyroid disease, and autoimmunity. Endocr Rev. 1993 Feb;14(1):107-20. doi: 10.1210/edrv-14-1-107.

11. Damara, Fachreza Aryo, Muchamad, Rizkania Ikhsani, Hendro ${ }^{3}$, Anisa Hana Syafiyah ${ }^{3}$, Muhammad Hasan Bashari. Thyroid disease and hypothyroidism are associated with poor COVID-19 outcomes: A 
systematic review, meta-analysis, and meta-regression. Diabetes Metab Syndr Nov-Dec 2021;15(6):102312.

12. Duntas LH, Jonklaas JJ. COVID-19 and Thyroid Diseases: A Bidirectional Impact. Endocr Soc. 2021 Apr 27;5(8): bvab076. doi: 10.1210/jendso/bvab076.

13. Liu Y, Sawalha AH, Lu Q. Covid 19 and Autoimmune disease. Curr Opin Rheumatol. 2021 Mar 1;33(2):155-162

14. Zou R, Wu C, Zhang S, Wang G, Zhang Q, Yu B, Wu Y, Dong H, Wu G, Wu S, Zhong Y. Euthyroid Sick Syndrome in Patients With COVID-19. Front Endocrinol (Lausanne). 2020 Oct 7; 11:566439. doi: 10.3389/fendo.2020.

15. Khoo B, Tan T, Clarke SA, Mills EG, Patel B, Modi M, Phylactou M, Eng PC, Thurston L, Alexander EC, Meeran K, Comninos AN, Abbara A, Dhillo WS. Thyroid Function Before, During, and After COVID-19. J Clin Endocrinol Metab. 2021 Jan 23;106(2):e803-e811.

16. Lui DTW, Lee CH, Chow WS, Lee ACH, Tam AR, Fong CHY, et al. Thyroid Dysfunction in Relation to Immune Profile, Disease Status, and Outcome in 191 Patients with COVID-19. J Clin Endocrinol Metab. 2021 Jan 23;106(2):e926-e935. doi: 10.1210/clinem/dgaa813.PMID: 33141191 Free PMC article.

17. Chen M, Zhou W, Xu W. Thyroid Function Analysis in 50 Patients with COVID-19: A Retrospective Study. Thyroid. 2021 Jan;31(1):8-11.

18. Prummel MF, Strieder T, Wiersinga WM. The environment and auoimmune thyroid diseases. Eur $\mathrm{J}$ Endocrinol. 2004 May;150(5):605-18. doi: 10.1530/eje.0.1500605

19. Mateu-Salat, M., Urgell, E., \& Chico, A. (2020). SARS-COV-2 as a trigger for autoimmune disease: report of two cases of Graves' disease after COVID-19. Journal of Endocrinological Investigation, 43(10), 15271528.

20. Jiménez-Blanco, S., Pla-Peris, B., \& Marazuela, M. (2021). COVID-19: a cause of recurrent Graves' hyperthyroidism?. Journal of Endocrinological Investigation, 44(2), 387-388

21. Feghali K, Atallah J, Norman C. Manifestations of thyroid disease post COVID-19 illness: Report of Hashimoto thyroiditis, Graves' disease, and subacute thyroiditis J Clin Transl Endocrinol Case Rep. 2021 Dec;22:100094. doi: 10.1016/j.jecr.2021.100094. Epub 2021 Aug 26.PMID: 34462717

22. Lanzolla G, Marcocci C, Marinò M.. Graves' disease and Graves' orbitopathy following COVID-19 J Endocrinol Invest. 2021 Sep;44(9):2011-2012. doi: 10.1007/s40618-021-01576-7. Epub 2021 May 8 .

23. Harris, A., \& Al Mushref, M. (2021). Graves' Thyrotoxicosis Following SARS-CoV-2 Infection. AACE clinical case reports, 7(1), 14-16

24. Lania, A., Sandri, M. T., Cellini, M., Mirani, M., Lavezzi, E., \& Mazziotti, G. (2020). Thyrotoxicosis in patients with COVID-19: the THYRCOV study. European journal of endocrinology, 183(4), 381-387.

25. Güven, M., \& Gültekin, H. (2021). The prognostic impact of thyroid disorders on the clinical severity of COVID-19: Results of single-centre pandemic hospital. International Journal of Clinical Practice, e14129.

26. Volpé R, Row VV, Ezrin C. Circulating viral and thyroid antibodies in subacute thyroiditis. J Clin Endocrinol Metab. 1967 Sep;27(9):1275-84.

27. Desailloud R, Hober D. Viruses and thyroiditis: an update. Virol J. 2009 Jan 12; 6:5. doi: 10.1186/1743422X-6-5.PMID: 19138419 Free PMC article. Review. 
28. Brancatella A, Ricci D, Viola N, Sgrò D, Santini F, Latrofa F. Subacute Thyroiditis After Sars-COV-2 Infection. J Clin Endocrinol Metab. 2020 Jul 1;105(7): dgaa276.

29. Asfuroglu Kalkan E, Ates I. A case of subacute thyroiditis associated with Covid-19 infection. J Endocrinol Invest. 2020 Aug;43(8):1173-1174.

30. Ashraf S, Imran MA, Ashraf S, Hafsa HT, Khalid S, Akram MK, Ghufran M, Cheema KK, Ahmad A, Izhar M. COVID-19: A Potential Trigger for Thyroid Dysfunction. Am J Med Sci. 2021 Sep;362(3):303-307.

31. Brancatella A, Ricci D, Cappellani D, Viola N, Sgrò D, Santini F, Latrofa F. Is Subacute Thyroiditis an Underestimated Manifestation of SARS-CoV-2 Infection? Insights From a Case Series. J Clin Endocrinol Metab. 2020 Oct 1;105(10): dgaa537. doi: 10.1210/clinem/dgaa537.PMID: 32780854

32. Ippolito S, Dentali F, Tanda ML. SARS-CoV-2: a potential trigger for subacute thyroiditis? Insights from a case report. J Endocrinol Invest. 2020, Aug; 43(8):1171-1172.

33. Grondman I, de Nooijer AH, Antonakos N, Janssen NAF, Mouktaroudi M, Leventogiannis K, et al. The Association of TSH and Thyroid Hormones With Lymphopenia in Bacterial Sepsis and COVID-19. J Clin Endocrinol Metab. 2021 Jun 16;106(7):1994-2009.

34. Fliers E, Bianco AC, Langouche L, Boelen A. Thyroid function in critically ill patients. Lancet Diabetes Endocrinol. 2015 Oct;3(10):816-25. doi: 10.1016/S2213-8587(15)00225-9. Epub 2015 Jun 10.

35. Trimboli P, Cappelli C, Croce L, Scappaticcio L, Chiovato L, Rotondi M. COVID-19-Associated Subacute Thyroiditis: Evidence-Based Data From a Systematic Review. Front Endocrinol (Lausanne). 2021 Sep 29;12:707726. doi: 10.3389/fendo.2021.707726.

36. Daraei M, Hasibi M, Abdollahi H, Mirabdolhagh Hazaveh M, Zebaradst J, Hajinoori M, Asadollahi-Amin A. Possible role of hypothyroidism in the prognosis of COVID-19. Intern Med J. 2020 Nov;50(11):14101412 .

37. Ilaria Muller, Daniele Cannavaro, Davide Dazzi, Danila Covelli, Giovanna Mantovani, Antonio Muscatello, et al. SARS-Covid-2 related atypical thyroiditis. Lancet Diabetes and Endocrinology. 2020 Sep;8(9):739741

38. Leow MK, Kwek DS, Ng AW, Ong KC, Kaw GJ, Lee LS Hypocortisolism in survivors of sever acute respiratory syndrome. Clin Endocrinol (Oxf). 2005 Aug;63(2):197-202.

39. Murugan, A. K, \& Alzahrani, A. S. (2021). SARS-CoV-2 plays a pivotal role in inducing hyperthyroidism of Graves' disease. Endocrine, 1-12.

40. Lan Wei ${ }^{1}$, Shen Sun, Cai-Hong Xu, Jing Zhang, Yun Xu, Hong Zhu, Suat-Cheng Peh, Christine Korteweg, Michael A McNutt, Jiang Gu Pathology of the thyroid in severe acute respiratory syndrome. Hum Pathol 2007 Jan;38(1):95-102. doi: 10.1016/j.humpath.2006.06.011. Epub 2006 Sep 25.

41. Tang C, Wang Y, Lv H, Guan, Z, Gu J. Caution against corticosteroid-based COVID-19 treatment. Lancet, 2020; 395(10239).

42. Jiang Gu, Encong Gong, Bo Zhang, Jie Zheng, Zifen Gao, Yanfeng Zhong, et al, Multiple organ infection and the pathogenesis of SARS. J Exp Med 2005 Aug 1;202(3):415-24. doi: 10.1084/jem.20050828. Epub 2005 Jul 25.

43. Lan Wei ${ }^{1}$, Shen Sun, Jing Zhang, Hong Zhu, Yun Xu, Qiang Ma, et al. Biochem Cell Biol 2010 Aug;88(4):723-30. 10.1139/010-022. 
44. Sriphrapradang C, Shantavasinkul, PC. Graves disease following SARS-CoV2 vaccination. Endocrine (2021). https://doi.org/10.1007/s12020-021-02879-8.

45. Zettinig, G, Krebs, M. Two further cases of Graves' disease following SARS-Cov-2 vaccination. J Endocrinol. Invest. (2021), https://doi.org/10.1089/thy.2021.0142.

46. Vera-Lastra, O, Ordinola Navaro A, Cruz Dominguez MP, Medina G, Sanchez Valadez, TI, Jara LJ. Two cases of Graves' disease following SARS-CoV-2 Vaccination: an autoimmune/inflammatory syndrome induced by adjuvants. Thyroid (2021),https://doi.org/10.1089/thy.2021.0142.

47. Sriphrapradang C. Aggravation of hyperthyroidism after heterolous prime-boost immunization with inactivated and adenovirus vectored SARS-CoV-2 vaccine in a patient with Graves' disease. Endocrine (2021). https://doi.org/10.1007/s12020-021-02879-8. 